\title{
trabalhenecessärio
}

issn: $1808-799 \mathrm{X}$

ano 5 - número 5 - 2007

artigo

\section{A EXECUÇÃo DE MAXIMILIANO (1868-9), DE MANET, COMO REFUNCIONALIZAÇÃo dO REGICÍDIO[I]}

Luiz Renato Martins[ii]

Para quem observa a obra de Manet (1832-83) e a história da arte moderna, o tema da execução de Maximiliano, tratado pelo pintor em várias versões, coloca-se como um emaranhado, freqüentemente evitado. Fica mais fácil dizer que o tema é acidental e não é representativo do restante da obra. Com efeito, há contra-sensos amalgamados há muitas gerações cobrindo essas telas. Vejamos alguns dos equívocos que marcaram época:

1) possivelmente nenhum outro tema terá recebido de Manet atenção tão insistente e cuidadosa. Ao longo de três anos (1867-9), Manet estudou e reelaborou o tema. As distintas e sucessivas versões caracterizam não um conjunto de telas, em princípio equivalentes, tal as vistas seriais da Catedral de Rouen (1894) por Monet, mas um trabalho em progresso. A tela final, hoje em Mannheim, é a resultante declarada. Manet nunca exibiu as telas precedentes.[iii] Não digo isso para diminuir o interesse dos trabalhos preliminares, e sim para ressaltar o empenho sistemático com que foi conduzido o processo de construção pictórica e sua conclusão. O pintor punha tal quadro num lugar superior dentro da sua obra.[iv] É uma suma poética e dela é preciso extrairmos os princípios e o desenvolvimento estético.

2) sabe-se que, antes mesmo de ser exibido, este quadro foi objeto de uma censura prévia. Em janeiro de 1869 o pintor foi notificado pelas autoridades de que não poderia exibir a tela nem as litografias correlatas. Zola denunciou o fato em artigo (La Tribune, 4/02/1869).[v] Para os contemporâneos era evidente a oposição da obra ao II Império. 
É paradoxal que mesmo este sentido dado, imediato, inerente ao tema tenha virado um incômodo para a maioria dos que estudaram a pintura de Manet após a sua morte. Não se reconhece o teor político da tela, como se este fosse acidental ou extra-pictórico e não o ponto de partida de um desenvolvimento sistemático.

A dificuldade é compreensível. O que fazer com esta série de pinturas de alto teor político, quando a obra de Manet era geralmente tida como não-narrativa, indiferente aos temas, proto-abstrata?

Igual dificuldade envolve outro conjunto de obras do pintor, com alta voltagem política, as litografias de 1871 em que Manet trata da Paris sitiada pelos prussianos, das barricadas e do massacre da Comuna. Desta feita coube ao regime republicano burguês e conservador que sucedeu ao II Império censurá-las.

Eis o paradoxo. Por um lado, um conjunto de pinturas com temas históricos, trabalhos elaborados com empenho e, no caso das litos de 1871 às custas de muitos riscos pessoais. E por outro a recusa cega dos especialistas.[vi]

O paradoxo persiste apesar destes trabalhos de Manet virem ganhando atenção desde a primeira exposição completa da série, ao lado de outros trabalhos de Manet com temas políticos, na National Gallery de Londres (julho-setembro 1992).[vii] O fenômeno persiste pois há um outro modo de negar estas obras.

3) O regime de negações do quadro é pois o terceiro ponto a merecer exame. Distinguem-se dois períodos, historicamente posteriores à censura política. As negações surgem postumamente, ligadas ao prestígio crítico do opticalismo ou da "escola dos olhos", como se dizia à época. A obra de Manet foi então vinculada ao impressionismo, paradigma da "escola dos olhos". Difundiu-se a noção de que os temas da pintura de Manet seriam anódinos ou ligeiros como eram os temas impressionistas.

A negação é obra do aparelho ideológico constituído pela crítica, pela história da arte e pelas direções dos museus, cuja influência é mais duradoura e persuasiva do que a censura. Se esta tinha um alcance sobretudo nacional - tanto é que em 1879 - dez anos depois (sic), Manet enviou a tela ainda inédita para ser exibida em Nova York e Boston -, já o domínio da negação de A Execução de Maximiliano é internacional.[viii]

O predomínio da doutrina opticalista/ formalista na interpretação da obra do pintor e de toda a arte moderna levou a que Manet fosse convertido nesta chave no marco zero da arte a-temática e anti-narrativa. E assim, junto com o complexo de significações realistas da obra de Manet que provinha declaradamente do fecundo núcleo romântico-realista da arte francesa - na raiz de Géricault, Délacroix, Daumier, Courbet ... - A Execução de Maximiliano e o todo da obra de Manet submergiram sob o consenso positivista de que 
seria uma arte radical e inovadora enquanto "anti-ilusionista" ou esvaziada de significação temática.

De acordo com tal visão, Malraux afirmou a respeito da tela sobre o episódio mexicano: "é o Três de Maio de Goya, menos o que esse quadro significa". E Bataille que retomou e citou tal juízo o ratificou em seu livro Manet (1955).[ix]

4) "Quarto terraço ou camada" da acumulação de contra-sensos. O ponto de vista formalista não prevalece mais. O dossiê Manet foi reaberto desde as grandes mostras em 1983 do centenário da morte do pintor, que ocorreram quando o paradigma formalista e o prestígio do alto modernismo, associados à abstração, já despencavam. Surgiram muitas leituras cujo denominador comum é a "contextualização", a remissão da obra de Manet às suas relações de origem.

Porém, salvo no caso de estudo que não terá chegado às minhas mãos, o problema persiste. A Execução de Maximiliano continua a ser negada, colocada como acidente ou enigma, nunca como momento de um sistema. Aceita-se que a obra de Manet comporte interesse semântico - tese para a qual, somando-se aos catálogos das mostras de 1983, o livro de Clark contribuiu. $[x] \mathrm{O}$ problema passou a ser hoje: o que significam a frieza e a indiferença com que Manet pintou tal tema, que ademais comoveu fortemente à época a imprensa e os meios governamentais europeus?

Manet executou o seu Maximiliano várias vezes ... A primeira versão começou a ser pintada nas semanas seguintes ao fuzilamento. As fontes iniciais são indiretas e não a sua observação imediata como haveria de ser para as litografias de 1871 e também para quase toda a sua obra. A Execução de Maximiliano apóia-se nos artigos melodramáticos e sensacionalistas dos correspondentes jornalísticos, da reconstituição gráfica dos fatos, das fotos que chegam pouco a pouco do México, etc.. Mas, na contramão destas fontes, o trabalho de Manet constrói outro tom e juízo dos fatos. Evolui para um tratamento frio e distanciado do tema, basta ver as etapas percorridas. Este o enigma.

O reacionarismo do aparelho ideológico burguês de leitura da arte - isto é, a crítica e a historiografia praticadas nas Nações centrais e as suas formas dependentes na periferia - alimenta duas linhas de resistência à leitura da tela. Constituem defesas, no sentido psicanalítico, que barram ainda hoje seu entendimento.

O primeiro dos bloqueios - arraigado entre historiadores franceses e ingleses mas também facilmente propagado alhures pois implica um tema-tabu, a "morte do pai" pela horda - envolve o regicídio.

Manet apresenta, com a frieza de um ato de rotina, uma cena de regicídio. Recordemos da fórmula hoje célebre, de Marx no 18 Brumário (1852) a respeito do golpe 
que entronizou Napoleão III: a história se repete não como tragédia e sim como farsa ... Na tela de Manet a repetição se dá como rotina. E a sublinhar o caráter da tarefa previsível e repetitiva, lá está, à direita de quem vê, o sub-oficial descrente dos primeiros disparos, preparando o fuzil para completar o trabalho.

Se o pintor esvazia a execução do tirano como rotina, na contramão, na recepção da pintura, o percebido é a questão traumática do regicídio que motivou a censura e a negação. O quadro caiu no abismo aberto entre o juízo histórico do pintor e o ideário antiregicida de historiadores e críticos. Sepultaram-no em silêncio e com o silêncio, censura muda.

Desnecessário insistir. Tudo o que se passou a partir de agosto de 1792 até o Termidor em 1794, incluindo, et pour cause, os regicídios de Luís 16 e de Maria-Antonieta em janeiro e outubro de 1793, foi condenado a posteriori pela historiografia francesa, salvo exceções honrosas, sob a divisa girondina de que era preciso "por fim à Revolução" e não prossegui-la como quis Gracchus Babeuf (1760-97).

Sirva de exemplo, no campo da arte, o caso de Jacques-Louis David, cujos trabalhos entre 1791 e 1794 são, na historiografia francesa oficial, classificados como "inacabados" ou esboços contingenciais - logo, relegados a minoridade poética.[xi]

A tela de Manet sofreu e sofre uma recusa de longa duração porque reabriu a caixa de Pandora dos pesadelos piores, vividos não apenas pela aristocracia mas pela burguesia que qual Macbeth identificou-se à classe que derrotara. E passou a augurar para si ambivalentemente destino similar ao dos reis. Associar a queda dos impérios negocistas à rotina, pior que vaticínio indesejável, é ironia corrosiva. Desapropria à burguesia neoimperial sua almejada identidade épica, identidade, reenviada ao sucesso passageiro nos negócios.

O segundo ponto de bloqueio reside na recusa à idéia da violência revolucionária como parte legítima do processo de descolonização; recusa que é geral entre os historiadores da arte dos países centrais.

Que fique claro. A provável empatia do pintor com a república revolucionária mexicana e sua concordância com a pena máxima para o tiranete - farsante imposto ao México pelas armas dos credores imperialistas (França, Inglaterra e Espanha) - nunca foi relacionada pelos historiadores, perplexos com o distanciamento da pintura de Manet. Ora Maximiliano encarnava a negação do desejo por um Estado descolonizado. Não era senão um imperador de aluguel, um títere dos predatórios contratos financeiros tramados por banqueiros e especuladores neocoloniais. Curiosamente, disto os historiadores da arte dos países centrais não conseguem cogitar até hoje - salvo trabalho que não me chegou. 
Deixemos esta geologia de equívocos porque o objetivo não é repisar a falta de credibilidade da história da arte. Investiguemos a veracidade do processo produtivo de Manet.

Qual era a perspectiva do pintor naquela altura? A primeira versão do quadro de Manet data, segundo estimativas, do período entre julho e setembro de 1867.[xii] Logo, o início do quadro é simultâneo à agonia do grande interlocutor e mentor de Manet, Baudelaire que desde o final de março vê sua enfermidade agravada e virá a morrer em 31 de agosto.

Não desejo propor nenhuma associação entre as duas mortes. Digo que a escolha do tema histórico e o seu desenvolvimento se fazem em meio a dor de Manet pela perda de Baudelaire. Constituem atos poéticos partícipes do trabalho construtivo do luto.

Para o pintor de 35 anos, quem sabe, o trabalho da perda enseja um passo maior. E este vem com a eleição de um tema que elabora criativamente uma das exigências do programa crítico de Baudelaire: uma épica cosmopolita, urbana e antiburguesa, moral e politicamente empenhada, a ser feita por "homens do mundo" e não por artistas ou virtuoses.[xiii]

Em "O pintor da vida moderna", ensaio publicado em 1863,[xiv] ano em que Manet estreante pintou Le Déjeuner sur l'Herbe, Baudelaire propôs de forma detida e acabada o que entendia por arte moderna. Mas a convicção histórica acerca da necessidade da arte se refundar manifestara-se desde o início de sua atividade crítica[xv] e desenvolvera-se nas duas décadas seguintes.

A consciência da base fundamental da arte moderna aclarou-se vivamente num dos primeiros textos críticos de Baudelaire: "Le musée classique du Bazar Bonne Nouvelle" (1846). A arte moderna, que o crítico exigia fosse épica, deveria se fundar nas "severas lições da pintura revolucionária". O Marat Assassinado (1794), de David, "poema inabitual" que "nada tem de trivial ou ignóbil", afirmava Baudelaire, é a origem, a "austera filiação" do "romantismo, esta expressão da sociedade moderna".[xvi]

O texto de Baudelaire é luminoso mas não há tempo para nos determos nos argumentos. Fiquemos porém com o exemplo. Situemos A Execução de Maximiliano à luz precursora do Marat ... e, por que não, também da Sagração de Napoleão (1806-7), ambos de David. Decerto nos catorze anos que separam as duas telas de David, a história da França moveu montanhas - mas interessa aqui que a ciência da tela de Manet tem um pouco de ambas: o olhar direto, rente aos fatos, do Marat ...; e a ironia glacial e a ambigüidade da Sagração...[xvii]

Os episódios originais destas três telas não poderiam ser mais diversos. Cenas 
políticas opostas separam-nos, mas o alinhamento proposto basta para distinguirmos que a tela de Manet compartilha com as duas telas acima de uma nova economia da pintura, aberta pelos trabalhos de David no período revolucionário e, que haverá também de incluir Géricault, Daumier e outros. Trata-se de uma nova economia e também de uma nova temática, a história, ela própria uma nova prática cognitiva, um novo saber.

Não estamos mais diante da pintura acadêmica de gênero histórico, hipocritamente edificante, à base de clichês neoclássicos e de referências à história antiga. Tampouco trata-se do caso das centenas de epígonos das academias restauradas, pompiers como Meissonier, que pululam ao longo do século 19 fazendo cenas militares contra o infinito... David, Goya, Géricault, Daumier, Manet ... pintam diretamente a história em curso e, de perto, como coisa próxima, aberta à ação do sujeito. Referem-se a fatos ou episódios candentes sob juízo público, combinados a tratamento e fatura pictórica autonomamente postos pelos artistas, responsáveis pela análise dos fatos, mesmo quando trabalham sob encomenda. Deste modo descrevem personagens contemporâneos e intervêm com procedimentos discursivos novos, entre os quais a análise da atualidade e o juízo reflexivo totalizante.[xviii]

A partir da Revolução Francesa, os pintores trabalham neste campo recém desteologizado, ao lado de escritores, historiadores e pensadores - por exemplo, os contatos entre Manet e Michelet são conhecidos.[xix] Elaboram um campo discursivo em formação: o da história como discurso laico, aberto, crítico e racional e também de choques ideológicos.

Tomemos tal hipótese. O processo evolutivo percorrido pelas diferentes versões de Manet tem o sentido de uma reflexão que progride no curso pictórico, combinada a um juízo crítico totalizante, uma reflexão histórica acerca da atualidade.

A primeira tela, hoje em Boston, parece evocar a primeira visão ou a vivência imaginária e sentimental de um ato de desordem: a fatura é nervosa e incerta, as figuras têm vultos indistintos, as vestes são tipicamente mexicanas - Manet, movido talvez pelos jornais que lera, parecia supor que o fuzilamento de Maximiliano fosse coisa de motim, obra de guerrilheiros ou de uma milícia civil de camponeses, e não de um exército regular do Estado republicano presidido por Juarez.

A segunda tela, hoje em Londres e da qual só conhecemos fragmentos reunidos postumamente, já comporta certos elementos da versão final: a composição é ordenada, os soldados pertencem a um exército regular, com uniformes similares aos dos exércitos europeus. Em suma o manejo do pincel já revela a ciência de que retrata um ato de Estado, de justiça marcial e não uma desordenada convulsão popular. As cores e seus 
limites determinam distintamente os corpos, as coisas e as partes. A composição delineia a posição do pelotão de soldados em termos já próximos aos da versão final, inclusive com a figura do sub-oficial à direita, esboçado na primeira versão, mas já agora bem plantado no seu encargo de concluir o ato, para o que engatilha o fuzil.

As maiores diferenças residem no entorno natural que envolve as figuras da segunda versão, hoje em Londres. O solo elevado, a linha alta do horizonte, realçada por cores claras, a cor forte do céu impregnam a cena de uma luz radiosa que confere certo ar de sublimidade, mesmo que barata ao modo de estampas populares. É como se a força vital da Natureza, sem ser contrastada por nenhuma construção, fosse a testemunha principal.

No colher a voz da Natureza, Manet se aproxima e se apropria talvez de um elemento central da tela de Goya sobre o "3 de Mayo",[xx] na qual uma elevação de terra ao fundo parece envolver os patriotas no seu manto, enquanto um céu sombrio e lúgubre paira sobre a cena. Mas se na execução retratada por Goya o papel da Natureza reveste assim um juízo moral, já no segundo esboço de Manet, agora em Londres, o sentido do fator natural é incerto e ambíguo. Assim, quando cotejamos este esboço de Londres com a tela final, de Mannheim, concluímos que faltam todavia certos passos importantes. $O$ trabalho não chegou a uma síntese entre a defesa da causa republicana mexicana e a construção pictórica em seus diferentes momentos. Aflora um resíduo de páthos indeterminado.

A tela final, de Mannheim, apresenta a organicidade de um resultado, na qual a evolução no tratamento de diferentes elementos se completa. Tudo se une e se determina reciprocamente e contribui para um complexo compacto de significações. O campo de visão e o ponto de vista, já esboçados na primeira versão, definem um olhar rente e direto, mais próximo aos fatos do que o da tela de Goya.

A visão curta e direta, que propõe uma proximidade viva e intensa - à distância de um braço, digamos - entre o primeiro plano e observador, já fora usada anteriormente por Manet, por exemplo, na sua Olympia. Como dispositivo pictórico, este modo de ver remonta, na França, ao Marat, de David, e mais longinquamente a Caravaggio. Sugere a participação direta do observador na cena. No caso de pinturas com alta voltagem política, como o Marat e A Execução de Maximiliano, o dispositivo assume conteúdo republicano; constrói visualmente o sentimento da ação histórica na primeira pessoa.

Em correspondência com o sentimento republicano, a tônica geral da pintura é fortemente racional. O quadro implica o ato do fuzilamento como exigência histórica ou necessidade lógica, sem dar lugar ao páthos das partes, ao melodrama que a imprensa na Europa fez do episódio. Para afirmar a racionalidade do ato, que é política, a pintura de 
Manet acentua os contrastes, dissocia as cores e determina os seus limites, individuando cada coisa. Impõe-se à vista a cinzenta geometria do muro ao fundo, imagem sólida e objetiva da lei, com a força de uma barra opaca e intransponível. Limitada por esta, vislumbra-se ao fundo uma nesga de céu, algumas árvores e uma faixa de terreno mais ao longe.

No 3 de Mayo, de Goya, terra e céu enquadravam o gesto humano. Já o entorno construído condiciona a apreensão de A Execução de Maximiliano. Sobressaem o solo limpo, a solidez do muro, a ordem social das coisas postas pelo homem. Não a Natureza e a ordem correlata da sublimidade mas a ordem espacial e política é que põe o terreno da significação.

Há também um Coro, mas sem a dramaticidade daquele que Goya incluira em seu quadro, solidário aos patriotas fuzilados. No trabalho de Manet, são populares encarrapitados ao muro, entre curiosos e indiferentes - um só que grita entre muitos. A composição, insisto, ainda sublinha a ausência de drama, mediante a figura do sub-oficial no primeiro plano à direita.

Sem cuidar do significado político da ironia glacial com que Manet tratara deste novo caso de magno regicídio - que num só golpe derrubava o irmão do imperador Habsburgo, Francisco José, e feria politicamente Napoleão III, o grande artífice em Paris da farsa imperial no México - os formalistas afirmaram que a pintura de Manet esfriava a cena representada, porque pretenderia se autonomizar (sic) da função narrativa.

Tratar-se-ia então, para eles, não de um juízo ou de uma leitura do fato histórico, mas de uma regra constante para o entendimento de Manet, artista anti-narrativo ao qual interessaria meramente o pintar. Na precipitação, os formalistas ignoraram também a ligação de Manet com Baudelaire, para quem, pejorativamente, o "artista" mero "especialista" da pintura, consistia "num homem atado à sua paleta como um servo atado à gleba", e analogamente, um pintor desligado do mundo político, num "cérebro provinciano", etc..[xxi]

O que nem os formalistas nem os demais historiadores europeus viram - com a eventual exceção de John House[xxii] que levanta o que denomina de ambigüidade da tela, não sem perplexidade - é que as modificações ou diferenças que a obra Manet apresenta frente à de Goya são precisas. Elas correspondem às significações opostas formuladas pelos pintores, diante do motivo. Se Goya pretendia suscitar repulsa ao fuzilamento, Manet, ao contrário, examina a cena com irônica frieza, condizente com o seu desfecho. A frieza de sua visão é refletida e tem antecedente: aquela de David, quando este, como regicida, fixou num desenho a figura de Maria-Antonieta, inimiga da Nação, conduzida pelas ruas de Paris ao cadafalso. Foi por vício e reacionarismo que os 
formalistas não consideraram que Manet tal como Daumier e Courbet herdara o sentimento regicida e revolucionário da I República.

A comprovação de que Manet não abdica da significação, mas a maneja segundo o seu entendimento do tema, fica evidente no caso das litografias sobre os massacres dos membros da Comuna pelas tropas de Versalhes.

O episódio se dá quatro anos após o fuzilamento de Maximiliano. Manet se apropria da mesma estrutura compositiva do quadro anterior, mas inverte o seu significado, o valor dramático das coisas. Na chave da defesa das vítimas, Manet se aproxima da veemência dramática de Goya e Daumier na luminosidade e na fatura. E de modo consoante faz o communard encarar o pelotão, levantar o braço e desafiar os carrascos de Versalhes.

O trabalho, em várias versões, em guache e aquarela e na forma de litografias, sublinha o sacrifício e a bravura dos populares, por um lado; por outro, o horror dos massacres. As janelas de Paris é que testemunham a cena. Mas diversamente do muro mexicano, severo ante à sorte funesta dos tiranos, a malha quadriculada das janelas, ao fundo, não surge geometrizada, mas sim tal uma fisionomia expressiva e solidária à resistência dos communards. Testemunhas da Comuna, memória tingida pelo sentido das coisas, as janelas revivem na visão dos observadores destas obras. Parecem vivamente nos fitar.

[i] Texto do trabalho apresentado no XXX Colóquio Internacional de História del Arte, Universidad Nacional Autónoma do México, Mexico, DF (8 - 11/10/06). Publicado em Mais Valia, novembro de 2007. Texto cedido pelo autor.

[ii] Doutor em Filosofia pela Universidade de São Paulo. Professor de Crítica e História da Arte do Departamento de Artes Plásticas da Escola de Comunicação e Artes da Universidade de São Paulo. Autor de Manet: Uma Mulher de Negócios, um Almoço no Parque e um Bar. Rio de Janeiro, Zahar, 2007.

[iii] Conhecem-se ao todo quatro telas e uma litografia: 1. (ca. jul - set. 1867), óleo sobre tela, 196 x 259,8 cm., Boston, Museum of Fine Arts; 2. (ca. set. 1867- mar 1868), óleo sobre tela, 193 x 284 cm., Londres, National Gallery; 3. (1868), Litografia. 33,3 x 43,3 cm., Amsterdam, Rijksmuseum; 4. (1868-9, esboço preparatório para o quadro final), óleo sobre tela, 50 x 60 cm., Copenhagen, Ny Carlsberg Glyptotek; 5. (1868-9), Mannheim, óleo sobre tela, 252 x 302 cm., Städtstiche Kunsthalle.

[iv] De acordo com Juliet Wilson-Bareau: "Manet considerava-a (a versão final de $A$ Execução de Maximiliano, 1968-9) uma de suas duas ou três pinturas mais importantes, e numa lista de trabalhos feita em 1872, ele avaliou-a em 25.000 francos, ao lado de $L e$ Déjeuner sur I'Herbe". Cf. idem, "Manet and the execution of Maximilian", in idem, Manet: the execution of Maximilian/ Paintings, Politics and Censorship, London, National Gallery Publications, 1992, p. 69.

[v] Para o texto da Gazette des Beaux-Arts (7/2/1869) que noticia a censura ver idem, ib.. 
[vi] Cabe ressalvar o estudo de Nils Göta Sandblad (Manet, Three Studies in Artistic Conception, Lund, 1954), ao qual não tive acesso e que parece ter sido o primeiro a destoar do consenso formalista.

[vii] Ver Juliet Wilson-Bareau, Manet: the execution of Maximilian/ Paintings, Politics and Censorship, London, National Gallery Publications, 1992.

[viii] Na França, a primeira exibição de $A$ Exdecução de Maximiliano só veio a ocorrer em 1905, no Salon d'Automne, em Paris. Após a exibição nos EUA, em 1879-80, a tela só foi re-apresentada quase vinte anos depois, em Londres, 1898. Ver John Leighton and J. Wilson-Bareau, "The Maximilian Paintings: Provenance and Exhibition History", in J. Wilson-Bareau, Manet ... and Censorhip, op. cit., p. 113, ver também pp. 69-70.

[ix] Ver Georges Bataille, Manet, int. Françoise Cachin, Genève, Skira, 1983, pp. 45-53.

$[\mathrm{x}]$ Ver Timothy. J. Clark, The Painting of Modern Life/ Paris in the Art of Manet and his Followers (1984), Ney Jersey, Princeton, University Press, 1989.

[xi] Ver, por exemplo, Antoine Schnapper e Arlette Sérullaz, Jacques-Louis David (cat. de l'éxposition), Musée du Louvre/ Musée Natiomal du Château de Versailles, Paris, 1990.

[xii] Ver J. Wilson-Bareau, "Manet and ...", op. cit., pp. 51-5. O fuzilamento ocorreu em 19/06, mas a notícia por cabo só chegou a Viena no dia 29. Napoleão III recebeu a notícia, por cabo de Viena, em 1/07, dia em que ocorreria a entrega solene dos prêmios da Exposição Universal pelo Imperador. Só no dia 5 ocorreu em Paris a divulgação oficial feita pelo presidente da Assembléia.

[xiii] Para a contraposição introdutória entre "homem do mundo" e "artista", ver adiante; ver também o capítulo III, "L'artiste, homme du monde, homme des foules et enfant", imediatamente anterior aos decisivos "La modernité" (IV) e "L'art mnémonique" (V) in Charles Baudelaire, "Le peintre de la vie moderne ", in idem, Oeuvres Complètes, vol. II, Paris, Gallimard/ Pléiade, 2002, pp. 689.

[xiv] "Le Peintre de la Vie Moderne" foi publicado em três partes no Le Figaro (26, 29/11 e 3/12/1863).

[xv] "(...)o heroísmo da vida moderna nos cerca e nos apressa (...) Haverá de ser o pintor, o verdadeiro pintor, aquele que souber extrair da vida atual o seu lado épico (...)". Cf, C. Baudelaire, "Salon de 1845" in idem, Oeuvres ..., op. cit., p. 407.

[xvi] Cf. idem, "Le musée classique du Bazar Bonne-Nouvelle", in idem, pp. 409-10.

[xvii] Para a dimensão irônica e a satírica deste quadro, "entre Goya e Balzac", e das suas figuras "endomingadas", ver Régis Michel e Marie-Catherine Sahut, David/ L'Art et le Politique, Paris, GallimardRMN 1988, pp. 105-7.

[xviii] Para este novo campo investigativo que Foucault denominou de "ontologia da atualidade" ou ainda "ontologia de nós mesmos", ver Michel Foucault, "Qu'est-ce que les Lumières?"/ "Qu'est-ce que les Lumières?" (in Magazine Littéraire, n. 207, mai 1984, pp. 35-39, extrato da aula de 5 de janeiro de 1983, no Collège de France), in idem, Dits et Écrits/ 1954 - 1988, éd. établie sous la direction de Daniel Defert et François Ewald avec la collaboration de Jacques Lagrange, vol. IV/ 1980-1988, Paris, Gallimard, 1994, pp. 562-78, 679-88.

[xix] Michael Fried esmiuça os laços entre Manet e J. Michelet (1789-1874), o historiador romântico, que em sua História da Revolução Francesa (1846/53) iniciara o resgate da Revolução e valorizara nesta o heroísmo anônimo do povo. Ver M. FRIED, Manet's Modernism or, The Face of Painting in the 1860s (Chicago and 
London, The University of Chicago Press, 1996, pp. 130-1, 404.

[xx] Manet esteve em Madrid em 1865. O livro de visitantes do Museu do Prado foi assinado por Manet em 1/9/1865. As obras de Goya comemorando o levante estavam expostas nos corredores, embora sem destaque. Ver J. Wilson-Bareau, op. cit., p. 45-7.

[xxi] Cf. C. Baudelaire, “Le peintre de ...”, op. cit., p. 689.

[xxii] Ver John House, "Manet's Maximilian: history painting, censorship and ambiguity" in J. Wilson-Bareau, Manet and the execution of Maximilian/ Paintings, Politics and Censorship, op. cit., pp. 87-111.

volta

file://C:Documents and Settings\AdministradorlMeus documentos\Minhas Webs\NED_.. 11/9/2008 